\title{
Editorial
}

\section{Dossiê: Educação, desigualdade e pandemia na América Latina}

\author{
Alexandra Lima da Silva \\ Ednardo Monteiro Gonzaga do Monti
}

O Brasil é o novo epicentro da pandemia. O país amarga o primeiro lugar no número de óbitos por Covid-19 na América Latina. No início de agosto de 2020, o Brasil chegou a marca de 96 mil pessoas mortas pela Covid-19. Enquanto muitos lutam para viver, o governo federal faz muitas propagandas. Nelas, o país é feliz, quase todos são brancos. A vida não pode parar.

Vivemos num país de propaganda.

96 mil Mortos? "E daí?”

Numa propaganda produzida pelo Ministério da Educação, jovens, majoritariamente brancos, defendem que apesar da pandemia, o Exame Nacional do Ensino Médio deve acontecer normalmente, pois "a vida não pode parar".

No vídeo, jovens de classe média, equipados com celular, macbook, câmera e muitos livros, interrogam:

"E se uma geração de profissionais fosse perdida? Médicos, enfermeiros, engenheiros, professores. Seria o melhor para o nosso país? A vida não pode parar! É preciso ir à luta, se reinventar, superar. Dias melhores virão. E por isso eu quero fazer o Rev. Caminhos da Educação: diálogos, culturas e diversidades, Teresina, v. 2, n. 2, p.1-4, mai./ago. 2020. 
exame nacional do ensino médio este ano. Para entrar em uma universidade. Estude, de qualquer lugar, de diferentes formas. Pelos livros, pela internet, com a ajuda a distância dos professores".

Para quem é essa mensagem? Para a juventude negra, periférica, estudante de escolas públicas? Certamente não.

Vivemos num país em que no ano de 2019, "apenas 55,1\% dos estabelecimentos públicos de ensino fundamental possuíam bibliotecas, 33,1\% apresentaram dependências adequadas para portadores de necessidades especiais, 44,3\% contavam com laboratório de informática, 57,6\% dispunham de internet em banda larga, 58,4\% não tinham rede de esgoto, e 6,1\% sem qualquer tratamento de resíduos. Acrescemos a isto o fato de que $34,2 \%$ das escolas, do mesmo nível de ensino, não possuem abastecimento regular de água” ANDRADE, Rodrigo Coutinho. Le Monde Diplomatic Brasil, 21/05/2020)

Para o ministro da educação do meu país, o Exame Nacional do Ensino Médio "não foi feito para corrigir injustiças sociais".

Os jovens pobres que lutem? Que se esforcem? Que se virem?

Após grande revolta e mobilização de parlamentares, o exame foi adiado. Apenas um senador, filho do presidente da república, votou contra o adiamento do exame nacional que determina quem poderá estudar em universidades no Brasil.

O país onde eu vivo, a maior parte da população é negra. Vivo num país em não se fala em reparação histórica pelas atrocidades cometidas pela escravidão.

No país onde eu vivo, as crianças negras não têm o direito de sonhar. E nem de existir. Na propaganda da "Pátria Amada", apenas crianças brancas, felizes. Elas olham para o futuro.

O direito de sonhar é um privilégio no Brasil?

Vivemos num país em que o sonho é privilégio, e tem classe e cor.

O direito ao sonho não pode ser privilégio. $O$ direito a vida não pode ser privilégio. O direito de sonhar não pode ter cor. Por um mundo em que todas as crianças possam brincar dentro de casa sem ter medo que os "homens de bem" as matem por serem negras e pobres. Sonhar já é um privilégio num país em que muitos não conseguem dormir.

Rev. Caminhos da Educação: diálogos, culturas e diversidades, Teresina, v. 2, n. 2, p.1-4, mai./ago. 2020. 
O país onde eu vivo se chama Brasil, onde o direito de sonhar é assassinado cotidianamente pelo Estado.

A bala.

Pelo vírus.

Pela fome.

Pela indiferença.

Pelo desgoverno.

Racismo mata.

Desigualdade social mata.

O Brasil é um país em que a pobreza, as desigualdades e o racismo são as maiores comorbidades. O Brasil é também, um país em que educadoras e educadores são tratados como inimigos. Como ensinar resistência para jovens e crianças que têm suas existências cotidianamente negadas?

Essa é uma pergunta que nenhuma propaganda dos órgãos oficiais do governo consegue me responder.

Considerando a importância do diálogo com outros países da América Latina, a editoria da Revista Caminhos da Educação: diálogos, culturas e diversidades organizou o dossiê Educação, desigualdade e pandemia na América Latina. O artigo Desigualdad y exclusión educativa en contexto de pandemia: Desafíos desde México, de Alejandro López de Lara Marín analisa o impacto da pandemia de Covid-19 num cenário de políticas neoliberais do sistema educativo nacional mexicano. O artigo Educación y desigualdade socioeconómica. Políticas públicas em tempos de pandemia (República Argentina), de Marité Preti y María Cristina Fernández apresenta os desafios das políticas públicas e de educação na Argentina, no cenário de Covid-19. O artigo Educar en tempos de pandemia: acentuación de las desigualdades en sistema educativo chileno, de Mabelin Daniela Garrido Contreras, procura caracterizar as desigualdades no sistema educativo chileno considerando o contexto prévio a pandemia, e o agravamento das desigualdades a partir dela. Katherine Hernández Morales explora os desafios enfrentados durante e depois à pandemia, e os enfrentamentos necessários ao combate das desigualdades e exclusão na República Dominicana, no artigo La educación antes y durante la pandemia del Covid-19: tejendo redes en medio de la desigualdade y la inclusión social en la Republica Dominica. Os desafios da educação superior na Rev. Caminhos da Educação: diálogos, culturas e diversidades, Teresina, v. 2, n. 2, p.1-4, mai./ago. 2020. 
Colômbia é o foco do artigo La educación superior pública en Colombia ante el Covid19, de Juan Felipe Quintero Leguizamon. Os autores Freddy Sánches Ibarra e Manuel Pérez-Troncoso refletem sobre o lugar dos professores como intelectuais no texto Irrupción del professora como intelectuales críticos en el contexto de pandemia, en buena hora!

A revista também publica três artigos de fluxo contínuo neste número. $\mathrm{O}$ artigo Duas mulheres educadas no oitocentos: registros em egodocumentos femininos, de Maria Celi Chaves Vasconcelos e Ana Cristina B. Lopez M. Francisco, analisa arquivos pessoais e egodocumentos elaborados por duas mulheres que viveram o Brasil do século XIX. Compreender as possibilidades teóricas e práticas para o trabalho com a diversidade musical em sala de aula é o foco do artigo A atuação do professor de música diante da diversidade musical: reflexões e possibilidades, de Alécio da Silva Veloso, Gabriel Sávio Vieira da Silva, Danilo Raposo Freitas e Gabriel Nunes Lopes Ferreira. Por fim, o artigo Entre memórias e histórias: a trajetória de formação e atuação profissional de uma professora acreana, de Mark Clark Assen Carvalo, Arnaldo Vieira de Morais, Adão Rogério Xavier Silva e José Pereira Flores aborda o processo de formação e desenvolvimento profissional no magistério, a partir da trajetória de uma professora acreana.

Deixamos o convite para a leitura deste número, organizado durante o isolamento social, em regime de home office, mas com a consciência de que não estamos dispersas/os.

Referências

ANDRADE, Rodrigo Coutinho. Professor delivery. A educação brasileira e a pandemia: breve olhar conjuntural. Disponível em: https://diplomatique.org.br/a-educacao-brasileira-e-a-pandemia-breve-olharconjuntural/?fbclid=IwAR3zcmqfIdSs-3Ejbej9ETcUtxMjI-

W0AzbLaMHSCWU54b7KIFoyMkb276M [Consulta em 29/05/2020]

Voz das Comunidades, Jornal, 21/05/2020

Rev. Caminhos da Educação: diálogos, culturas e diversidades, Teresina, v. 2, n. 2, p.1-4, mai./ago. 2020. 